\title{
Playful and Playable Lighting in Smart Cities: Towards a Holistic Framework of Design
}

\author{
Henrika Pihlajaniemi and Aale Luusua
}

1 Abstract In this chapter, we will explore the phenomenon of playful and playable lighting in smart cities. We will describe and discuss participant experiences of playful and playable lighting based on the design and evaluation processes of four case studies. These studies, we argue, provide aspects of participation, communication and self-expression; experiences of the sense of place, meanings and beauty; and activities of play and physical exercise. We will look at these case studies, and the aspects of playfulness and playability, through the lens of both smart city literature and relevant theories, and the practical experiences from the processes, examining also the afterlife of the case studies. We reflect on the presented case studies and their experiential aspects, asking: How can playful and playable lighting be made viable in a city? Finally, we conclude by presenting a design framework which consolidates aspects that, we argue, should be acknowledged, considered and addressed in the design and decision-making processes of smart cities, neighbourhoods and urban places in order to create playful experiences of playable urban lighting in a viable way.

Keywords Playable lighting · Playful lighting - Smart city • Adaptive lighting • Interaction $\cdot$ Participation $\cdot$ Design framework

\section{\& 1 Introduction}

\section{H. Pihlajaniemi ( $\varangle)$}

Oulu School of Architecture, University of Oulu, Oulu, Finland

e-mail: henrika.pihlajaniemi@oulu.fi

\section{A. Luusua \\ Oulu School of Architecture/INTERACT, University of Oulu, Oulu, Finland \\ e-mail: aale.luusua@oulu.fi}


smart city development. In our research, we have been interested in exploring the change from static lighting to dynamic, adaptive, intelligent, interactive and participatory lighting, and how this influences urban inhabitants' multifaceted experiences of light in urban spaces and their experiences of the urban environment in general $[23,33]$. For example, are these new types of lighting changing the way various kinds of individuals experience and use the city and urban places, and what do we know about the city? In addition, a key question has been how the knowledge and understanding of users' experiences can guide the design processes in order to create well-being in smart cities.

Due to their practice and user oriented nature, the methods we have utilised in our nearly a decade's worth of research into the subject have been very concrete: firstly designing and building pilot installations in real world settings, i.e. in different kinds of urban environments; secondly, researching various individuals' experiences with qualitative and participatory methods; and finally, reflecting on the design outcome and design process and analyzing participant data with grounded theory approach and through relevant theories. While our experience has gradually unfolded itself through these design explorations and participant studies, these new non-static lighting installations in urban environments have opened up many aspects of playful behavior and features of playability we now reflect upon in this chapter more carefully. The overall aim in this chapter is to create a design framework for viable playful and playable lighting. This will be achieved through a twofold approach. Firstly, we will illustrate through case studies experiential aspects which are related to use of playful and playable lighting in urban space. Secondly, the reflection of the projects, both at the time of completion and now looking back after some years, has revealed several critical issues and points of pain besides positive experiences. These critical aspects, many of which have been also raised in the literature of smart cities in a wider context, will be scrutinised and discussed in the chapter. The experiential aspects form a fruitful design potential, which with the understanding of the critical design aspects will aid designers and policy makers in integrating playful and playable lighting into future smart cities in a viable way.

Playable lighting can be defined as a part of a playable city. Playable city, according to Nijholt [29], refers to a smart city, which opens its processes, infrastructure and data through applications of smart technologies to be modified by the citizens and used in user-based ways to improve the inhabitants' daily lives in the city. These applications could be implemented in a playful and humorous way. Generally, we could define playable city or playful city as a city which generates well-being by supporting children's and adults' play and by allowing them to behave playfully in its places. Play can be considered to relate to six defining features: "spontaneity and intrinsic motivation, lack of practical goal or benefit, actions or thoughts in novel combinations, repetition of thoughts and actions, [...] well-being" and behaving and thinking in a spontaneous and flexible manner (Nijholt [29], referring to Bateson and Martin [1]). Continuing from the aforementioned, we could define 'playful and playable lighting' as lighting, which, firstly, supports play in cities and playful behaviour of people; secondly, behaves itself playfully; and/or thirdly, allows citizens to modify and use it themselves in a playful way. Additionally, applying the 


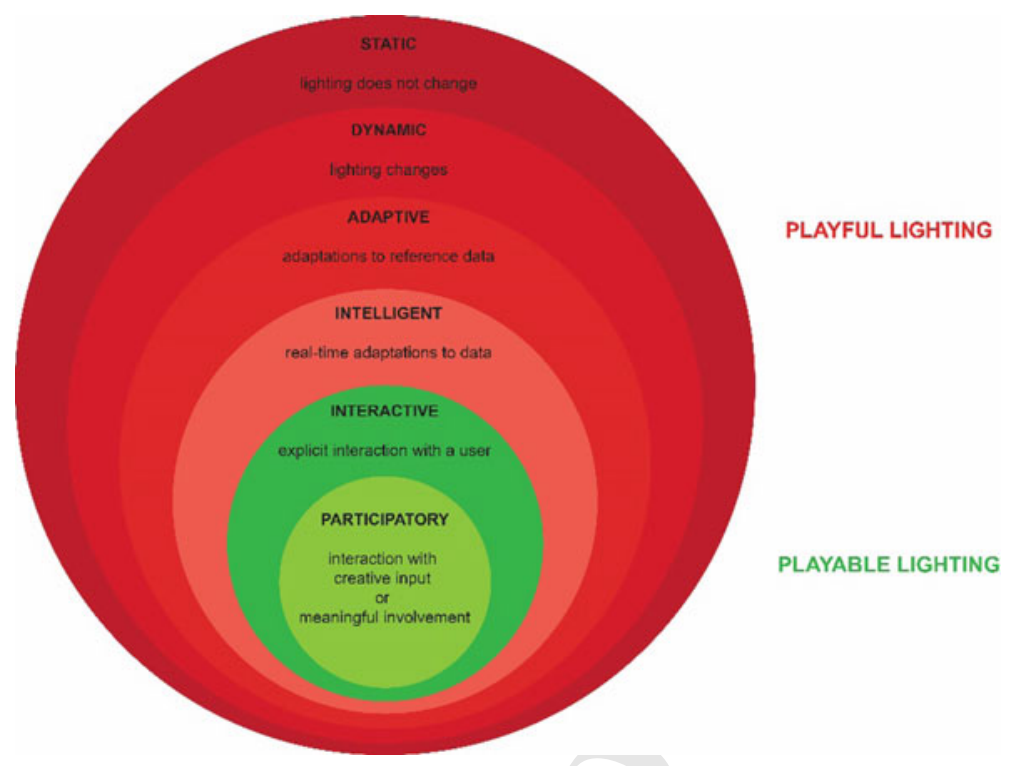

Fig. 1 Playful and playable lighting positioned in the conceptual framework of the lighting types based on new lighting control technologies. Illustration adapted from Pihlajaniemi [33: 18]

definitions by Bateson and Martin [1], playful and playable lighting can support actions with spontaneity and intrinsic motivation and it induces actions which may lack practical goal or benefit. Furthermore, it can support novel combinations of actions and thoughts, actions relating to well-being, and spontaneous and flexible behaving and thinking.

In order to understand the new concepts of lighting created by the emergence of control technologies, and how they relate to the playful and playable features of lighting, we employ here the categorisation presented in Pihlajaniemi [33:18] and illustrate the concepts in Fig. 1 and in the following description.

Traditionally, artificial lighting has been considered as a static element in nocturnal urban environments: at the cessation of daylight, lights are turned on, and they continue to illuminate steadily through the night, and turned off at sunrise, respectively. With control technologies, dynamic changes are enabled in lighting. When these changes are related and responsive to reference data, lighting is considered to be adaptive. These adaptations may occur to many kinds of data, for example, to presence data or to an idealised model of dynamic changes of the light spectrum and intensity during a day. When these adaptations happen in real-time and are based on analysis of the data, adaptive lighting can be considered intelligent. Further, adaptive and intelligent lighting is interactive, when there is explicit user interaction as part of the adaptation process. This can mean, for example, adjusting lighting with a mobile phone application to suit one's needs. Additionally, when a user interacts with lighting and creates something meaningful, for example, artistic as an outcome, 
Fig. 2 Even static lighting can sometimes have playful expressions. The Figures project by Sami Huuskonen was designed for Helsinki World Design Capital 2012 event. The movable, humoristic lighting poles are owned by the city of Helsinki and they have adventured in different locations around the city. Photographer Ilpo Aalto, published on courtesy of Tehomet $\mathrm{Oy}$



adaptive and interactive lighting is participatory. Now, continuing further, we add to this conceptualization the notions of playful and playable (Fig. 1). Even static lighting can sometimes express playfulness, as the humoristic luminaire poles of Fig. 2 present. However, the dynamic and adaptive technologies widen the range of possible expressions by introducing playful lighting behaviour into designers' toolkits. These lighting behaviours can in themselves be playful, bringing enjoyment, visual interest and atmosphere into urban spaces through a dynamic play of light, shadow and colour. This playful lighting can exist without conscious interaction and participation of urban inhabitants. It does not need any effort or input from users of public spaces but can still bring them pleasure or invite them to play or even dance in the streets (Fig. 3). However, playable lighting, we argue, as a form of interactive and participatory lighting, requires people and their playful interaction to exist (Fig. 4).

In the following sections, we will first, in Sect. 2, describe and discuss experiences of playful and playable lighting based on the design and/or evaluation processes of four case studies. These cover aspects of participation, communication and selfexpression; experiences of the sense of place, meanings and beauty; and activities of play and physical exercise. In Sect. 3, we will look at the cases and the experiential aspects of playfulness and playability through the lens of both smart city literature and relevant theories and the practical experiences from the processes and the afterlife of the case studies. We reflect on the presented cases and the experiential aspects, asking: How can playful and playable lighting be made viable in a city, especially in the long term? In the final section of the chapter we conclude by presenting a design 




Fig. 3 Playful Lighting. Dynamic lighting in a park route, which has disco-like, playful behaviour with rhythmically changing bright colours. Even though the lighting is not interactive, it can invite people to dance in the streets. Urban Echoes project will be presented as a case study in Sect. 2

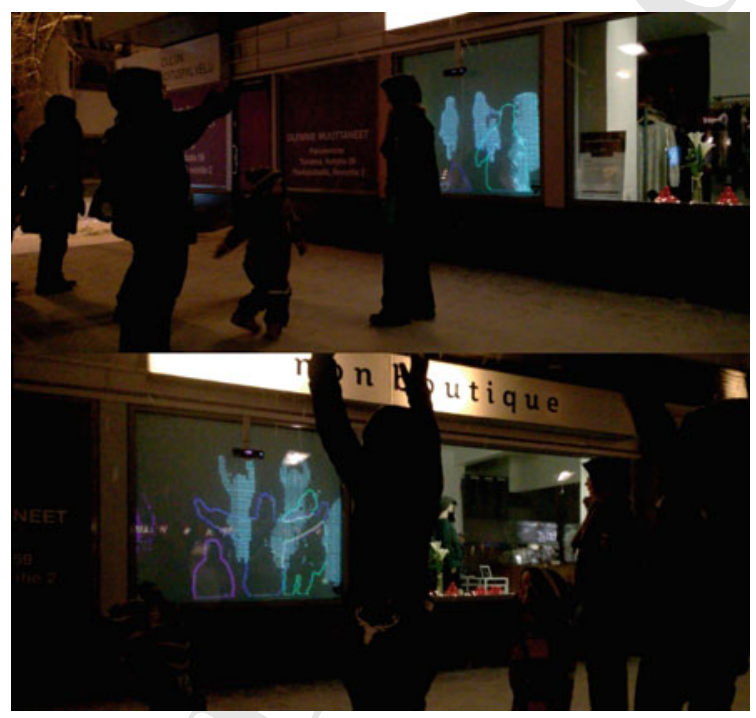

Fig. 4 Playable lighting. Participatory light art by John Collingswood engages people to interact with people in another street. Lumo Light Festival 2018, Oulu

framework which collects the aspects, which we argue, should be acknowledged, considered and addressed in the design and decision-making processes of smart cities, neighbourhoods and urban places in order to create playful experiences of playable urban lighting in a viable way. 


\section{Experiences of Playful and Playable Lighting in the City}

\subsection{Communication, Participation and Self-Expression}

The first case study we will present and discuss is the LightStories project $[33,36]$, conducted in winter 2011-2012. The pilot project was part of a four-year research project, where we collaborated with the city authorities and lighting companies. The main aim of the research project was to develop methods and design tools for adaptive lighting and to study the city inhabitants' experiences of new lighting solutions in different kinds of urban environments. We got a suggestion from the representative of the city planning office that we could do something in a pedestrian-oriented street in the city centre, where new lighting with controllable RGB LED strips had been installed in 2009. Despite having a controller unit with many functionalities, the lights had only been on with blue or white light for some years. Only the decorative light elements-RGB LED light strips along the sides of the luminaire poles-were controllable and not the functional street lighting.

We were confronted with a problem, which is currently fairly common, where the city had developed a controllable lighting system in an urban space and the authority to use it was more or less undefined: no one had neither a clear responsibility, the will nor the time resources to decide how the lighting was controlled and to perform the necessary actions for controlling it. What would be a meaningful appearance and functionality for the lighting, instead of the static blue light, which was there only because no one had bothered to change it? We came up with an idea of opening up the lights in the public street to city inhabitants' own control, thus involving citizens to participate in designing the temporary appearance for the street at night-time. Additionally, we were interested in the communicative potential of lighting: how to invite people to express themselves and communicate with the light in a public space and how to support this communication with other media, with electrically published textual narratives? Light has a long history of being a medium of communication, stemming perhaps from the ancient systems of warning fires, which alerted urban inhabitants to approaching invaders from a distance. Today's cityscape is equipped with lights which signal to us how to behave in traffic, warns us of danger by vehicles, and attract us to consume with their luminous messages.

In order to meet our design targets in a playful way, the interaction concept of a web-based design tool, which allowed the users to compose their own lighting design - to play with colours, effects and rhythms - was created. In addition, the LightStories concept included sharing the stories as texts and real-time videos in the web site as well as publishing the texts in the public touch screens, UBI displays, in the city centre (Fig. 5). These screens accompanied by a free wi-fi, PanOulu, were part of Oulu's smart ubiquitous infrastructure which helped Oulu to be selected into Top Seven Intelligent Community in the World 2012 [30].

In February 2012, the LightStories project was in operation during a period of 25 days. In the test period, 105 user-generated dynamic lighting designs were displayed on the pedestrian-oriented street. The participants' experiences and feedback 

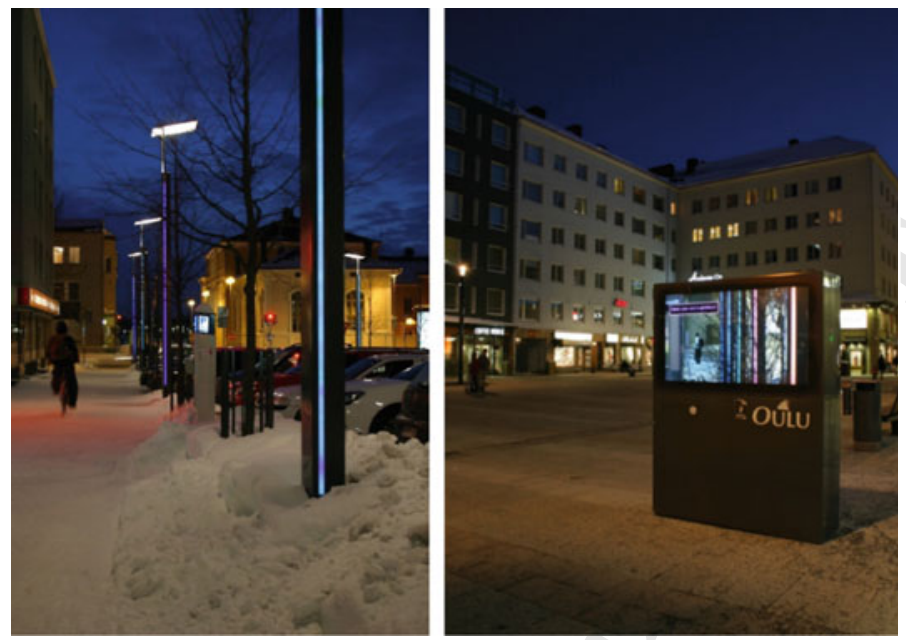

Fig. 5 LightStories project. A LightStory as seen in a streetscape: a one-hour long animation of the colourful lights composed by a participant. The accompanying textual narratives could be read in public touch screens of the city centre or in the web-page

on the project were collected with an online questionnaire, which was part of the procedure of making a LightStory (a lighting scheme and a published text), and with a semi-structured interview, where volunteer participants were invited. Additionally, the system use data and the LightStories, which had been created, were collected and analysed. A thorough description of the evaluation and analysis of the results is detailed in [36]; in the following, then, we will discuss some of the key findings.

According to the participants, LightStories was seen as a fun, interesting, exciting and easy way to involve the citizens with urban lighting and with the design of their own environment. Only a small amount of negative feedback was given; according to these, the participation through LightStories was complicated, boring, or did not meet the participant's expectations. The participants motivations to participate included both the pure pleasure of playing with light and colour and the pleasure of writing and publishing a story. Some were curious to find out how they could make a LightStory. Other motivations, which came up in the interviews, were the will to send a message to fellow citizens and to have an influence on their own environment and to enhance space visually.

Communicating with light and colour was seen as very important and also rewarding, and the tool enabled participants to create a wide variety of unique lighting designs. Many participants visualised parts of their textual narrative through the rhythm and colours of light. With the lighting, participants expressed e.g. feelings, political opinions, memories etc. Even though playing with light was seen as fun by many, the expressed feelings sometimes also had darker tones as they ranged from joy to bereavement. In this way, play as an action is not only for joy, but can be part of a grieving and healing process. 
Several participants used LightStories for greetings, which often marked special dates, or were just meant to bring joy to a close person or to the people of Oulu. Published texts also included shorter greetings and longer stories, which described, for example, a memorable situation in the writer's personal history (e.g. the memories of a summer holiday in Oulu in the 1950s, a story of two swans which the writer had taken care of throughout one winter), a topical theme (election day), or simply the writer's current state of mind. The participants had varied attitudes towards the textual part of LightStories: some participants found it very inspiring, an important part of the process, and also useful as aiding the design; however, for some the play with light and colours was the primary part, and writing and publishing something was seen as unimportant, or as even an unpleasant necessity. Overall, the verbal and visual part complemented each other, attracting people with different strengths and abilities, and enabling users to express themselves accordingly.

The LightStories project is an example of lighting which is both playful and playable. A passer-by can just enjoy the animations of light on the street, even without knowing the idea of the project. The knowledge, however, turns the passive role into active one, and a street walker or a citizen in general becomes involved with participatory light art as he or she starts wondering what the story behind the lighting is, and perhaps checks it from the website and even wants to participate in the playing and make his or hers own LightStory. Through the act of participation and social creativity, playable lighting can create a more meaningful relationship to an urban area. It can increase participant's awareness of the area and improve their opinion of it, teaching people to think differently about their environment. In the LightStories case, the playable lighting resulted in a stronger identity for the street in their minds.

The playful method for participation could be used to engage people in improving the quality of public urban environments by reporting of places, that need some fixing or improvement, and suggesting actions and solutions for developing the city. This strategy was envisioned in the Ituita-Congonhas Media Cascade project [42]. An example of a participatory demonstration applying playable lighting as projections was the Climate Wall, which was in operation during the climate conference, Beyond Kyoto, and provided citizens of Aarhus with the opportunity to participate in the ongoing climate debate. Passers-by could move projected words on the façade of Ridehuset, and create sentences relating to climate and carbon emission [9, 14].

\subsection{Sence of Place, Aesthetic Experience and Meanings}

The second case study project, Urban Echoes, was a temporary park lighting installation, which was so well-liked that it finally remained functional for two winters (February 2013-May 2015) in the centrally situated park in Oulu, Finland. We had several research aims associated with the project. One starting point was that we were developing a graphical tool for designing adaptive and playful behaviour of lighting, which would react to people's presence and movements (VirtuAUL by Toni Öster- 
lund and Henrika Pihlajaniemi, published in $[31,32,37])$. The idea was to employ algorithms so that the emerging lighting behaviour would contain features which would be reminiscent of natural light phenomena and surprise and delight users' of urban spaces, besides supporting functional lighting needs. Thus, we used the park path as a testing zone for different lighting behaviours; in the park, there was no risk of accident with vehicles moving with fast speed. Furthermore, we could compare different adaptive lighting behaviours starting from a very straight-forward logical behaviour to more playful uses of light. For the testing, our park lighting installation was designed as a flexible system programmed to produce both even distributions of light and more uneven distributions consisting of different-sized patches of light on the park pathway and also emphasis on surrounding birch trees. Besides white light, colours were possible due to the RGB LED luminaires.

We were interested in studying how the different variations of lighting would change the character of the formerly little-used pathway, and the park users' experiences of lighting and the urban environment. The park's central location, coupled with a questionable reputation as a result of some past crime incidents [19], made it an interesting site for our tests. We had an opportunity to study, for example, ways to enhance the experiential quality and the feeling of safety in the park. Furthermore, we continued here studying the theme of communicative lighting. In this case, however, we did not allow people to communicate themselves through light but used the installation to provide urban information in the form of colourful lighting. In the installantion's default lighting mode, the effect colour of otherwise warm white lighting was indicating the temperature of the air with a colour scale (Fig. 6). Park users also had the possibility to be more active and interact with lighting in order to make it communicate other things. With their smartphones, people could make inquiries about current events in the city (Events mobile service) and the real-time activity levels of several locations in the city centre (Activity mobile service); they received an answer visualized as light playing on surfaces of the park path and trees around. The users could also read the same information in graphical and textual form on their mobile devices and continue to read more detailed information of the events. The third section of the mobile service—Lighting — provided a real-time visualisation of the lights and how much energy they consumed. Park users could access the Urban Echoes mobile service on the spot through scanning the QR codes on site.

In the evaluation of park users' experiences, we employed a mixture of qualitative methods, which we call experience gauging walking interviews, to enable broader knowledge and interpretation of people's experiences. These were preceded by a preliminary interview. Our participants (15 in walking interviews) consisted of two age groups: young adults (20-29 years) and seniors (over the age of 65). We wanted to compare two clearly different groups, with different abilities to see and move and readiness to use digital technologies. The experience gauging walking interviews were participant observations combined with a semi-structured walking interview carried out on site with researcher-designed lighting scenarios (Fig. 7). We ran 14 different movement-adaptive or dynamic lighting scenarios and two mobile service based communicative lighting schemes while walking the path back and forth and discussing several themes related to lighting with our participants. The evaluation 




Fig. 6 Urban Echoes. The park path with the default lighting indicating the outdoor air temperature with colour coding



Fig. 7 Some of the tested scenarios during experience gauging walking interviews

methods, the lighting scenarios and the results are described in detail in [23, 24, $33]$; in the following we will discuss the results from the perspective of playful and playable lighting.

The interviewees had generally positive attitudes towards the use of adaptive lighting in park environments, and they saw it as beneficial in many ways. For example, the energy-saving aspect due to the absence of light or lower light levels when the park was unoccupied was seen as a positive value. This value was present in all the movement-adaptive scenarios, but by introducing the scenarios of more playful forms of adaptation after the first two scenarios with a very basic type of lighting, the participants found other new values in the lighting, as well. Interviewees valued many of the playful scenarios for their aesthetic character and the atmosphere they created to the urban nightscape. This was seen especially important in Finland's climate with its long and dark winter. For them, it was seen to provide a comfort- 
able feeling and add well-being. Only one out of the 15 interviewees did not see this as being relevant and found the playful and aesthetic behaviour unnecessary in the park, but preferred the basic, strictly functional type of lighting. Generally, the only doubts presented by participants towards this type of new lighting technology were about the reliable operation and endurance of intelligent lighting systems and whether possible maintenance problems would cause costs to citizens.

The basic purpose of pathway lighting in parks is to enable park users to move safely and comfortably in them. Movement-adaptive behaviour was generally seen as a pleasant and good way of illuminating. Many participants mentioned the importance of anticipative behaviour, i.e. light being always brightened ahead a walker, and not only where a walker is going. Also the perceptible, dynamic changes of light and the use of colours-as long as this type of playful behaviour was not too rapid-were seen as positive features. However, certain colours (yellow and yellowish green) in a scenario of only coloured light lessened the visual perception of the path for some interviewees. In addition, some doubts were expressed concerning whether the lighting would react in a right pace for cyclists, who would be moving with a faster speed than walkers.

Movement-adaptive lighting was seen by several participants to enhance the sense of security in the park, and it was associated, for example, with the feeling of light preceding one. Additionally, the fact that movement-responsive light could reveal the presence of possible aggressors, had a positive effect to the sense of security. Interestingly, one participant described how she realised during our walks in different types of lighting that it was not the amount of light which mattered, but the atmosphere and sense of a specific place which was created by playful lighting and the use of coloured light, had a positive influence on the feeling of security. Sense of security was, according to some interviewees, context-related. The quality and familiarity of the environment, the surrounding light levels, activities, and social context, in general, were seen to influence sense of security.

In the participants' answers, playful features of lighting induced aesthetic experiences: the lively, dynamic patterns of light, reactions to one's own movements, the constellations of small luminaires above the path reminiscent of a starry sky, the illuminated trees, and especially the use of coloured light in the scenarios. The playful lighting scenarios created many associations in the participants minds. Many associations were related to nature, for example, to aurora borealis. Other associations or meanings that emerged were, for instance, rag rug, disco and game-like feelings of moving in a constantly metamorphosing labyrinth. The atmospheres created by adaptive and playful lighting made the park a more meaningful place to the interviewees, and they could give it an own new identity, as was the case also with LightStories.

All the interviewees found the idea of connecting information to park lighting interesting and saw positive values in it. The idea of lights communicating the prevailing weather or forecasting it was favoured by many. The legibility of the visualized information provided was an important issue, concerning the Events and Activity services. Supporting information for decoding the message should be on site. Participants presented further ideas for communicating with adaptive lighting, which were 
more participatory, for example, communicating ethical and ecological values-a personal demonstration. Also changing the colours of the park to express personal feelings and to create atmospheres was seen as interesting.

Urban Echoes was not clearly playable lighting, as the interaction possibilities and chances to really play with the light were limited. The interaction with movementadaptive lighting of the park could be described as implicit interaction, as the system was responding by adapting the lighting behaviour to users' needs based on their location, without any explicit effort or command [41]. The participants experienced this implicit interaction generally in a positive way; however, some interviewees were also wishing for more explicit interaction with light through gestures and movements, which would have allowed them to consciously play with lights. Furthermore, many appreciated the mobile-device-based explicit interaction through the Urban Echoes services; nevertheless, also wider interaction possibilities would have been appreciated. Especially the young interviewees envisioned creating designs with park lights and playing and composing with colours in the role of a light-DJ.

The installation with playful lighting scenarios changed the character of the Otto Karhi park in terms of park-use. We spent altogether more than fifteen hours walking in the park with the interviewees, which gave us good insight into the changed social context. As indicated in the observations, the park had become a more active place where many spontaneous actions happened, in spite of the harsh winter conditions. The amount of people using the route increased clearly and people were, besides walking and watching the lights play, taking photographs, sitting on the bench, having a picnic, playing with lights, dancing, and staging cosplay (short for costume play). Once in the park, an old lady came to ask who had designed the lights and thanked for how much they delighted her. She told that she walks along the park every day, as she lives near and that she had wiped off the snow from the tree light boxes every time she walks through, so that the lights will not be snowed under. This gesture showed that adaptive and playful lighting can arouse feelings of belonging and positive communal identity, which increases concern over common public environment.

\subsection{Play and Exercise}

Finally, we introduce the theme which is perhaps the most obvious form of experience concerning playable lighting: the play. How to induce actions of play in urban space with the help of light? We discuss here some projects from this perspective.

Finland is a country where urban lighting is on and needed mostly when it is cold outside. Especially in northern Finland, where Oulu is located, a warm and dark evening or even night is a rarity. On the other hand, we have long, dark winters with snow coverage, which makes an excellent background for projections of coloured lighting. In the middle of long darkness and coldness, people need playful activities which attract them to spend time outside and physical activities, which make them move and keep them warm. The SnowLight project grew from this background. 




Fig. 8 SnowLight. Bodily interactions with light

Besides enjoying winter sports, snow is a material to build from. During winter months 2013, the Lumimaailma (Snow world) installation-a construction made of snow and ice, was situated on a marked place by the seashore of Oulu. The installation is meant for people - especially children - for climbing and sliding in the snow, and for enjoying the soundscape composed for the event. We created there an interactive and participatory light project, to attract people to use the snow installation during the dark time, as well. Thus, the lighting was physically playable with bodily activities, but had also other participation possibilities, which added other layers of playful use in the installation (Fig. 8).

The RGB LED lights of the installation were controllable by visitors through the public touch screen situated on the market place, which allowed the users to choose colours for the lights. In addition, the lighting interacted as animation patterns with people climbing up the wall and sliding down the snow hills. The soundscape also influenced lights in one part of the installation, creating rhythmical alterations of light based on the music. Visitors were encouraged to take photos of the installation and of the interacting people, and to send them to be projected onto the adjacent theatre wall, as well as to be published on the public touch screens. These projections added an extra level to the interactive play of light, as the observers were attracted to join the game and to communicate with light in pictorial format. One aim of the project was to increase the citizens' use of public touch screens, the smart city infrastructure of that time. We assumed, that the process of seeing real-time interactions with light according to one's own design in public space, would be rewarding enough experience to attract users to the system [38].

The installation was used by children and their parents also during the dark time, so the lighting made a day-time playable urban space attractive in the evening, as well. The participatory system was also used, and the colours of lights were changed every now and then. However, it is hard to say, how much did the interactive behaviour 


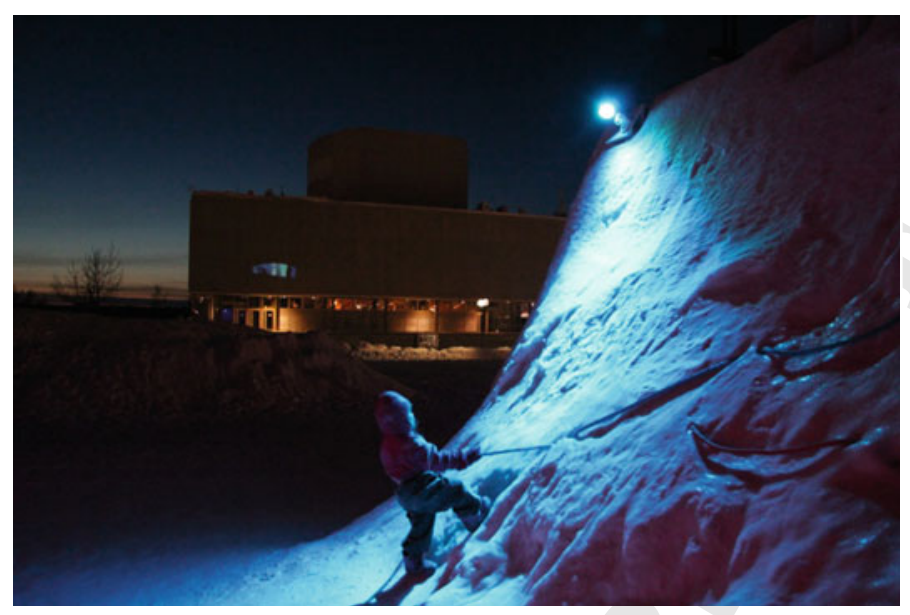

Fig. 9 SnowLight. Climbing wall. The theatre with the wall projections is in the background



Fig. 10 SnowLight. The colour scheme of the installation was regularly changed by the users of the market square

of light while sliding down really add interest to the play and exercise or would the children have gained the same pleasure with static coloured lighting or with playful dynamism of light without any interaction. The photo projection part of the project could not be considered a success: besides the photos by a member of the research group no others were published (Figs. 9 and 10).

Within the SenCity research project (2015-2017, www.sencity.fi), we got the chance to study the potential of intelligently controlled lighting and permanent smart city infrastructure for creating active play in an urban environment. The project was based on the idea that, in cities, lighting poles always situate in the locations where people move and act, and thus they offer a network of optimally situated electricity 
supply as well as communication near people. These networks could be employed for installing different kinds of sensors which gain and analyse data in real-time for smart city services. In this way, the intelligent lighting infrastructure could form a service platform - an Internet of Things backbone-in an intelligent city. In the SenCity project, intelligent lighting solutions and user-centric digital services were piloted in different kind of urban environments. Collaboration was done between research partners, companies and six cities of various scales around Finland [35].

Lahti, a city in southern Finland with 120,000 inhabitants, was a partner city in the research project. Lahti's pilot area was a promenade along the harbour of the lake and it was developed into an active recreational environment for citizens. The area had an interesting history with an important inland harbour, rail traffic, and industry. The old lighting for the route was inefficient and light levels low. Part of the $1.5 \mathrm{~km}$ long route located in the middle of the industrial backyard-type area and the lighting conditions made those parts of the route feel uncomfortable and even frightening for users at night. The route was used regularly as a thoroughfare and a recreational route.

As part of the development of the area, the old lighting of the route is being gradually replaced with new one, at the same time updating the infrastructure with new features: the lighting will be a combination of LED route lighting with intelligent control and PIR sensors for presence detection, and effect lighting of coloured light projections on ground using RGBW LED spotlights and DMX control. In addition, base stations for a free WiFi connection, web-cameras, loudspeakers and assembly spaces for extra sensors will be integrated in the smart wooden lighting poles developed by the project partners. During the project, we involved city representatives, business partners, and users of the area in a user-centric design and development process, aiming to gain insight from the local people about the present state of the design area and their ideas for its development. The details of the participation process and the resulting designs can be read in [34], nevertheless, here we want to present a design concept for LightGame, which was developed for the Harbour Promenade (Fig. 11), applying the smart infrastructure.

In the participation process, a wish to use the lighting in activating children and other visitors in the physical sense came up. The resulting light game application concept developed by the research group was designed to allow gamers to chase dynamically living light dots on the ground and to earn points and rewards basing the interaction with light technologically to GPS location analysis of the mobile devices in the pocket. The principle combined the game activities in the physical real-world settings to augmented reality functions in a mobile phone. The principle has similarities with Pokémon Go game application, which makes players to walk even long distances engaged in the chase of virtual creatures, Pokémons. However, with the LightGame, the players' actions do not only influence the virtual world by earning points and seeing rewards as augmentations on the mobile phone, but also change the elements in the real world, namely the visible lighting effects. The LightGame project is not yet realised as there has been delays in refurbishing the promenade and constructing the new smart infrastructure. 


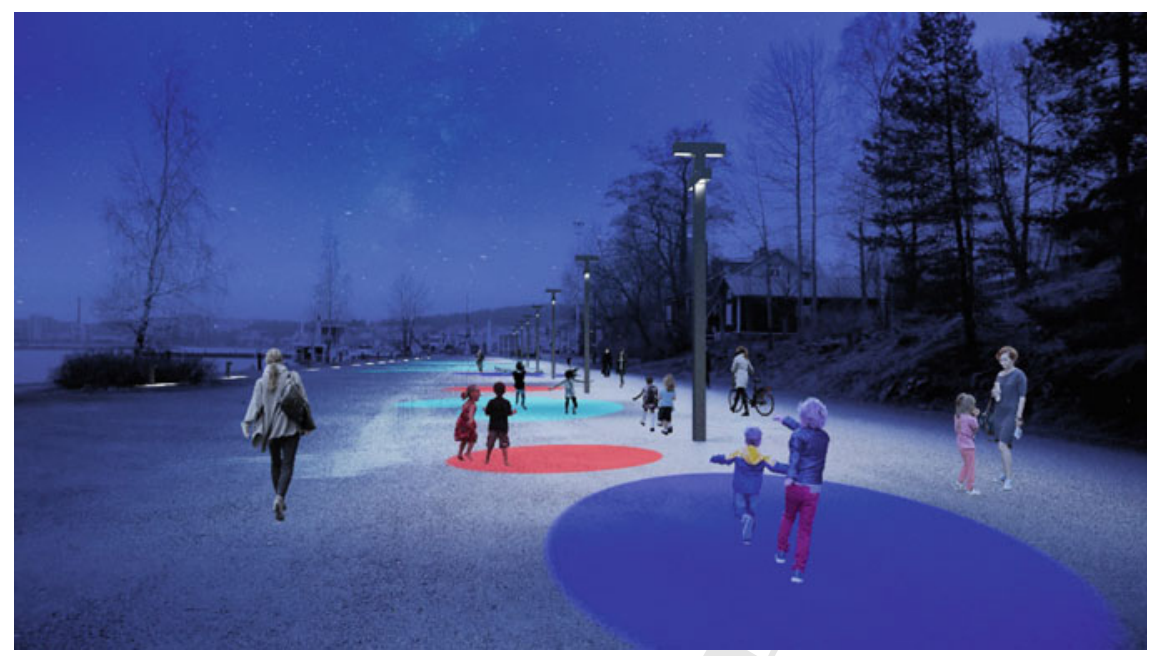

Fig. 11 Vision for LightGame in Harbour Promenade, Lahti

Figure 12 summarises experiential aspects of playful and playable lighting that we have identified through the analysis of the four case study projects. In the case of playful lighting, city dwellers' role can be described as a spectator, whereas with playable lighting, the role can be considered a participant. However, this division is not abrupt but sliding and both roles can coexist. In the figure, also the listed aspects of experience-place, expression, meaning and play-have their subtle variation in relation to playable and playful lighting. These different manifestations of the same experiential feature can exist also in parallel. Play is listed here as one feature of experience in order to emphasise our finding that the experience of playful and playable lighting is multifaceted and not only covers purposeful play or game activities, but playful behaviour or experience can be found in many situations.

The LightStories project as an example of playable lighting demonstrated how participation created strong ownership to the streetscape for the people who themselves made their own unique lighting to the street, taking over the smart city infrastructure for their own purposes. Their participation involved self-expression and creating meanings, as they actively played with the design tool composing dynamic expressions of the street lights and published their narratives. However, the LightStories project can be viewed also from the perspective of playful lighting and from the spectator's role. The streetwalkers could enjoy the playful behaviour of light without participating in or being aware of the project and it was creating a sense of place for them. If they, on the other hand, were familiar with the project, they could check the stories on-line and receive meanings that the participants had created.

In Urban Echoes project, which can be considered playful lighting, park users could enjoy aesthetic expressions of light and receive meanings, such as learn about weather of the day. In the interviews, lighting in the park was considered as something 


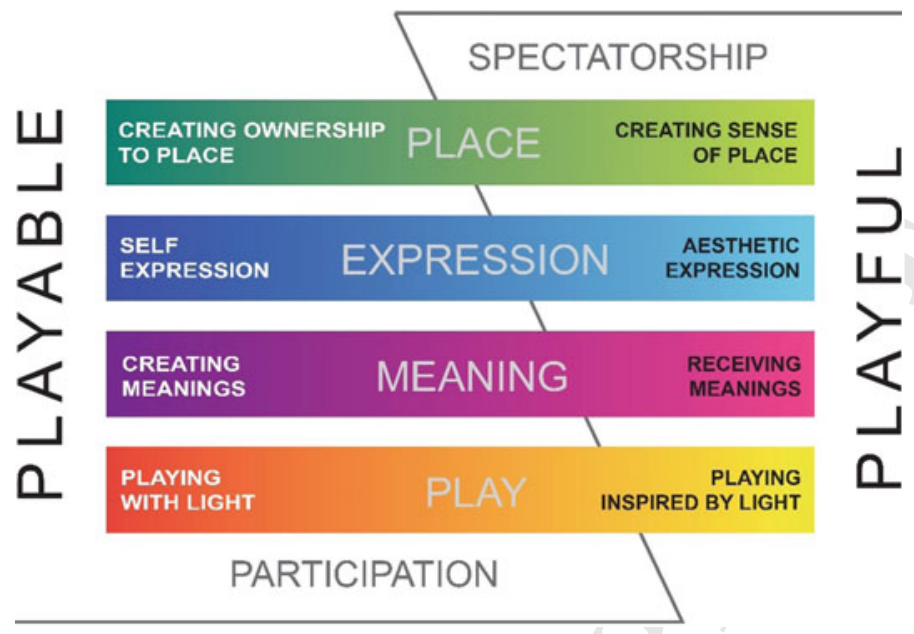

Fig. 12 Experiential aspects of playful and playable lighting

to come to see for its own sake and to bring friends to enjoy. This spectatorship role was observed in the park many times, as single people, couples and families were witnessed having evening walks there and taking photographs. This brings up the notions of "noctambulisme" [2]—walking around in the city at night for its own sake-and "nocturnal tourism" [28], which are not new but emerged already with the spreading of electric light and illuminated billboards into urban landscapes.

Even though Urban Echoes project was not designed as playable lighting in the same sense than LightStories and Snowlight, where users could participate in playing with lights with a design tool or user interface, or like LightGame in Harbour Promenade, where users were envisioned to actively play and interact with moving lights in the urban space, its playful lighting succeeded in changing the behavior of park-users, and inspired them to play with lighting by dancing, for example. The playful lighting changed their behavior to a more spontaneous and playful direction and had an influence on the sense of place in the park, as explained above.

\section{Critical Design Issues in the Smart City: Viable Playful and Playable Lighting}

We have now shown through many examples how playful and playable lighting is related to many positive experiences in urban environments and how it can enrich the urban life, increase well-being and make citizens engage with their environment. In this section, we continue the reflection of the case studies and discuss also with a wider perspective the big question: How to make playful and playable lighting viable? 
Socio-cultural viability: One of the most important and problematic issues when it comes to designing and implementing playful and playable urban lighting, is the issue of cultural fit of the content and mode of interaction that is produced. This is due to the fact that-through control technologies-urban lighting is actually rendered into a medium, i.e. it is able to encode and express cultural content. This begs the design question of what kind of content should be displayed? And how can this content remain relevant in a long-standing installation? As playable lighting needs participants in order to be successful or even exist, a truly viable, long-term installation of playable technology in the city has to solve the issue of cultural relevance; or alternatively, as in the case of lighting festivals and events, make novelty and impermanence an essential, intentional part of the installation. Novelty has always been a factor in our case studies as well. LightStories showed us clearly that media visibility had a crucial influence on participation activity. A permanent installation would not have had the benefit of media interest. Long-standing installations of playable lighting are a remaining design challenge from the point of view of cultural viability. However, based on our work on urban technologies, we argue that a key design strategy to address this issue is to study and consider the cultural continua that are already present in and close to urban spaces, especially those that relate to urban playfulness. For example, a temporary installation that supports dancing in the street is clearly possible also in the cold, snowy conditions of northern Finland, as we saw with Urban Echoes. However, it would form an even more plausible concept for a long-term installation in the urban squares of China, where especially elderly people often gather to socialise and exercise through synchronised group dancing (e.g., [7]). Similarly, there are many practices in the West that are similarly existing cultural practices with long-standing, year-round traditions. SnowLight inspired adults and children to play together in a way that made cultural sense in wintry Finland; snow castles and sledding are activities that never go out of style. This might well be extended to year-round play in urban playgrounds, skate parks, picnics places, etc. Similarly, by moving our attention to animals, we might be able to support the play of dogs and their owners, a growing pastime in Western countries. The design strategy, then, is to recognise these continua of (playful) practice both on national as well as the local level and to design for them.

However, these issues are also temporally affected. If the interactive content is permanent, who is responsible for maintaining it? If the content is temporary, whose task is regularly producing the new content or organizing and ordering the process of developing new playful and playable concepts using the infrastructure? In many city organizations, these responsibilities are not clearly defined, or resources are not associated for this work, which leads to underused infrastructures. Returning to our first case study, the seemingly successful LightStories, the current state at the street is rather illustrative in this respect. After the pilot project ended, the lights were set to a white colour for half a year. Then for a light festival in November 2013, a collection of LightStories that people had made was set there as a repeating program, which made the street look playful and colourful again. These colourful animations remain there still, as nobody in the city organization has had the knowledge nor time to do there anything. Passers-by do not remember why the lighting is animated 
like that. Gradually the RGB LEDs, which were purchased at 2009 representing the newest technology of that time, have started to die making the image of the nocturnal streetscape messy and ill maintained. In this way, the technology and playful content, which first upgraded the urban space and its image among city dwellers, is now due to bad maintenance degrading the image of the area.

Economic viability: This aspect of technical and content-related maintenance is related to another crucial aspect for playable lighting, i.e. the economic viability of these installations - how can projects be funded in a sustainable way? Again, most of the well-known published projects that present intriguing examples of playable lighting are temporary, usually associated with an event lasting from couple of days to a month; most notably, these take place in light festivals. Cities worldwide are willing to invest public money in light festivals (Fête des Lumières in Lyon, Lights in Allingsås, Lux Helsinki, Glow Festival in Eindhoven, Vivid in Sydney, Luminale in Frankfurt, Valon kaupunki in Jyväskylä, etc.), which repeat year after year, and seem to grow steadily and succeed in attracting many visitors, some local but many even international. The same phenomenon is happening in our own city, Oulu, where Lumo Light Festival (www.ouka.fi/lumo) will have its seventh anniversary in November 2019. Last year, the festival reached 150,000 visitors in its various events [20]. Besides through public and third sector funding, festivals are also often sponsored by the marketing budget of private companies, which gain visibility through the event. The playful and playable lighting installations, which provide entertainment and pleasure for citizens, are realised by artist groups who offer their services as readymade packets for cities to purchase, thus not demanding a great deal of human resources or expertise from the city. In the short term, then, the issue of economic viability seems to have been solved. Once again, the issue, however, becomes more complex and the challenges larger when we think of playful and playable lighting as a permanent part of a city. Many, if not most, cities and communities want to be and be seen as smart cities (e.g. [16]). Lighting, then, can be seen as a part of the smart infrastructure of a city, where lighting poles and data networks become a backbone of the IoT (Internet of Things) infrastructure, where data is collected, analysed and used for different kinds of services. This, of course, offers many possibilities for playful and playable lighting solutions, as was shown in the Harbour promenade case. The question, however, emerges: who should own this infrastructure? How should its purchase be funded? How should it be maintained? Certainly, over the last decades, some very effective business models have sprung up around digital technologies in general. Simply put, the common model in digital services, introduced after the Dot Com bubble in the 1990s, is essentially an exchange where companies provide services, and users generate and provide a constant stream of personal use data for marketing purposes (customer behaviour analysis and prediction). Before this model was invented at Google (and subsequently introduced to Facebook and others) the company nearly toppled, despite its global reach and status as an industry-leader. Zuboff has argued that this novel business model has even created a novel form of capitalism, surveillance capitalism [48]. Can-and should-public infrastructure, such as playful and playable urban lighting, follow these business models where users' sometimes intensely personal data is exchanged for services? This is a question 
that emerges as urban infrastructures begin to informate [47], i.e. have the capacity to not only deliver information through it, but to also provide information about its use, i.e. to conduct a form of surveillance. This ability to conduct data-led surveillance has been a concern since Clarke [8] coined the term 'dataveillance' nearly two decades ago. Thus, to argue for smart city technologies is to argue for an environment where everything is able to informate and conduct dataveillance, urban lighting included. This is an important question in smart city research, and, thus, for the research of playable lighting as well. It is no wonder, then, that critical smart city scholarship has recently focused heavily on the economical basis of smart urban technologies (e.g. [6, 16, 27]). However, it should be noted that this ability is not inherently a part of only market economy; a notable example is China, where dataveillance in public urban places is being heavily pushed by the government [39]. What is important to realise, then, that the necessity to fund playful and playable urban lighting may lead to unintended Trojan horse scenarios, where dataveillance is discreetly incorporated into public places.

Ethical viability: The financial and ethical viability aspects of information (i.e. informating) technologies, then, are very closely intertwined through the issue of privacy. One of the main concerns here is that playfulness and playability, attractive qualities across various demographics, might be used to cover up privacy-breaching or otherwise undemocratic practices, intentionally or-as the case may be-unintentionally in the pursuit of offering otherwise viable installations. Other important aspects relating to ethical viability often have to do with inclusivity (e.g. [4]), which may or may not happen at several levels: on societal as well as the everyday level. In our case studies, the aspects of playfulness and playability were crucial in motivating citizens to take an interest in urban lighting and urban places. Thus, we can see a clear potential for the democratic inclusion of everyday citizens in smart city place-making and co-creation through the aspects of playfulness and playability in urban lighting. However, designers should bear in mind that the participation that the playfulness supports should ideally have a genuine, beneficent [45] purpose; at the very least, it should not be used as a token gesture to avert attention away from important issues $[6,27]$, but rather, to highlight them.

Yet this is only one aspect of inclusivity, which takes many forms. As a public good, urban lighting could theoretically be used in a low-threshold manner. Similarly, it should be located equally in problematic and unproblematic urban spaces. Certainly, in the Urban Echoes case our participants' views of the park, which, as we had priorly mentioned, had an extremely bad reputation as a site of rape incidents [19], improved significantly. This indicates that playful lighting might be a tool that could be utilised to improve places with negative identities.

A further issue to consider is the suitability of the installations to many kinds of potential users, including those who are not able-bodied, or may otherwise feel excluded from public urban places. Safety, feeling of security and accessibility must be considered. While all our case studies touched on these issues, especially the senior participants in the Urban Echoes study brought these issues forward on many occasions. These were detailed in [24, 33]. 
Material viability: Upkeep of permanent and semi-permanent physical computing infrastructures in a city is a perennial problem, especially due to the vastly differing time scales that are present in urban planning [25]. Issues that have to do with the material viability of playful and playable urban lighting encompass the activities and objects that occupy the same urban spaces as the technologies, and the very real and prosaic issues of material upkeep and climate-resistance (we have explored this from the point of view of other urban technologies in [44]). These are issues of fundamental importance. In our case studies, this was always present, sometimes even humourously: one of our Urban Echoes participants reported that whilst passing through the park previously, she had stopped to clean some accumulated snow off our luminaires that were on the ground. This was kind and touching, but obviously not all individuals do share her community-minded approach. Playful and playable urban lighting should be designed with upkeep in mind, taking into account the natural and human elements, even vandalism.

Technological viability: Software updating and maintaining technological functionality in general, is a challenge for long-term installations of playful and playable lighting. As with other smart city technologies, the time-scales of city-making and software-making are vastly different (we have explored this in conjunction with urban displays in [25]). The planning and design processes for public urban places may take years. However, in the world of digital technologies, new software updates, new versions of hardware and even entirely novel devices and systems are released in close step with quarterly business cycles. This puts pressure on any socio-technical systems that utilise digital technologies. This issue can only be addressed through the adequate allocation on resources, leading us, once again, to the aspect of economic viability in the design of these systems.

Ecological viability: It has been pointed out by many design scholars that the interdisciplinary field of design is inherently anthropocentric, and that this is also a major underlying factor in the design of smart cities. In the age of climate change and the destruction of species, many scholars in the smart city research community have discussed modes of design that would either take into consideration other life-forms, or even de-centre humans as the focus of design $[10,12,26]$. Indeed, the effect of lighting on humans and other life-forms is profound (cf. Ergonomic viability), and thus, any truly ecologically viable form of playful and playable lighting must consider and support the well-being of the non-humans and the world in which it is placed, whether its site is an urban park, a suburban street, or ski resort in the "wilderness". Foth and Caldwell [13] have reminded of three critical aspects in this respect in the context of media architecture, which are applicable here: light pollution, energy consumption and e-waste. International Dark-Sky Association (IDA) defines light pollution as inappropriate or excessive use of light, which includes "Glare-excessive brightness that causes visual discomfort, Skyglow—brightening of the night sky over inhabited areas, Light trespass - light falling where it is not intended or needed, [and] Clutter - bright, confusing and excessive groupings of light sources" [17]. In addition to the fact that more than $80 \%$ of the world population lives under light-polluted skies [11], light pollution has several negative impacts to wildlife and the ecosystem [13]. 
Another ecologically crucial design issue is energy consumption. Even though the change into LED lighting aims to reduce energy consumption, a rebound effect has been discovered: in a study period from 2012 to 2016, Earth's artificially lit outdoor area grew by $2.2 \%$ per year, and the total radiance grew by $1.8 \%$ per year [21]. An ecologically viable design for playful and playable lighting must consider methods to decrease both energy consumption and light pollution in the form of skyglow. Again, this design issue relates to time: with the intelligent lighting control technologies it is possible to conceive lighting schemes, which operate only when needed. For example, it is unnecessary to have lights playing along a park route, when no one can see them. In Urban Echoes project, the playfully living light dots appeared on the park route surface as someone was entering the park. If no one was present as monitored by PIR sensors, there was only an evenly distributed route lighting with a low illuminance level not to make the path look dark and uninviting. Even though the intelligent technology often solves problems, it may easily lead to another ones. The smart solutions are composed of, besides LEDs, of many other digital devices, cables, sensors and electronic components. The abundant use of digital technology is gradually leading to rare earth materials depletion and after the material or technological aging of the devices and components, to the unethical dumping of this e-waste to developing countries [13].

Ergonomic viability: Closely relating to the above discussion of the negative influences of light pollution on flora and fauna, we want to continue with still one critical design perspective-ergonomics. Even though ergonomics is often linked to working environments [5], it can be expanded to cover all the situations where people are interacting with machines or artefacts in general [40], in this case, with playable lighting technologies. As a scientific discipline and design field, ergonomics (or human factors) aims to optimise human well-being and make systems and environments compatible with the needs of people [18]. The International Ergonomics Association (IEA) raises up two domains within ergonomics, which are of special interest while designing playable lighting: physical ergonomics and cognitive ergonomics.

Zielinska-Dabkowska [46] has discussed many critical aspects of Media Architecture using light in the context of public spaces, which can be applied here in relation to playable lighting. Light has influences, both negative and positive, on human health and well-being. Physiologically ergonomic design prevents, for example, negative effects to safety by glary light sources or visually distracting content in screens. A connection between increase in traffic accidents and the presence of electronic signage and advertisements has been indicated in $[15,43]$. The glare is not only an issue of safety, but it can cause visual discomfort for users of the city [3]. Besides glaring light sources, ill-designed dynamism can cause disturbance or even health problems, such as an epileptic seizure. This was an aspect which we took into consideration while testing to find the suitable parameters for light dynamism so that the users could not create stroboscopic effects or other unpleasantly fast changes of lighting while using our LightStories design tool. Furthermore, in the Urban Echoes project, we tested several playful lighting scenarios with our participants. Even though one of the scenarios literally made passers-by to dance thus inducting playful behaviour, it was clearly pronounced in the interviews (by smiling or laughing participants) that 
this kind of hectic dynamisms of bright and highly-saturated, coloured lights— "disco lighting" - could not be considered as a permanent solution, but only for an event or New Year's celebration etc. This again raises up the question of temporality: whether we design playful or playable lighting solutions for permanence or for temporary, short occasions? It can be seen that the design criteria are slightly different in those cases. In lighting design field, a concept pair sparkle and glare is used to illustrate that even the same absolute brightness of light can cause either positive experience or negative experience, respectively, depending on the context. A bright object, which is beautiful and found meaningful and relevant to the context or situation can be considered attractive and enjoyable and is referred to sparkle [22]. In the same way, tolerance to glare and light disturbance is higher when it is a couple of days' light festival in question than with permanent installations. Obviously, in Urban Echoes case, we did not choose the disco-light to stay in the park for two winters, but chose deliberately a scenario which offered, besides the pleasure of playful dynamisms of light, visual comfort for the park-goers. Nevertheless, maintaining visual comfort in urban space and prevention of light disturbance to neighbouring apartments are important design issues with temporary installations, as well.

Finally, playful and playable lighting should not create excessive cognitive load for urban dwellers of different ages but to create interest, excitement, humour and enjoyment into urban space in a balanced way. It can be refreshing to be involved in playing with light or engaged in solving a riddle of lighting behaviour or a humoristic message in a screen, however, if these repeat every day and in many locations around city, will it turn to a strain? How long does the same joke, even good and clever, make one laugh? As the prices of screens and other media technology products are going down, we are witnessing their spreading into every street corner and side of a square in marketing purposes. Thus, while designing playful and playable lighting applications in already technologically crowded smart cities, it is necessary to consider the impact of each new lighting system and application to the overall image and the legibility of the city [46]. For viable designs, it is crucial to choose the right context for the playful and playable lighting projects and to integrate their design from the initial design steps into the wider design processes of urban space and architecture.

Figure 13 summarizes the design aspects that we have discussed in this section. As we noted above, many of the aspects are temporally affected. Even though the aspects are relevant in both temporary (one time or reoccurring) and permanent installations of playable and playful lighting, the design strategies addressing these issues may differ. In the figure, seven design aspects that were scrutinized above, are stretching between the time axis poles temporary and permanent. The features of each aspect, which should be considered in creating design, realisation and maintenance strategies, are gathered along the axis. 


$\begin{array}{lcr}\text { - NOVELTY } & \text { SOSIO-CULTURAL } & \text { - CULTURE } \\ \text { - OUT OF CONTEXT } & \text { VIABILITY } & \text { - CONTEXT-RELATED }\end{array}$
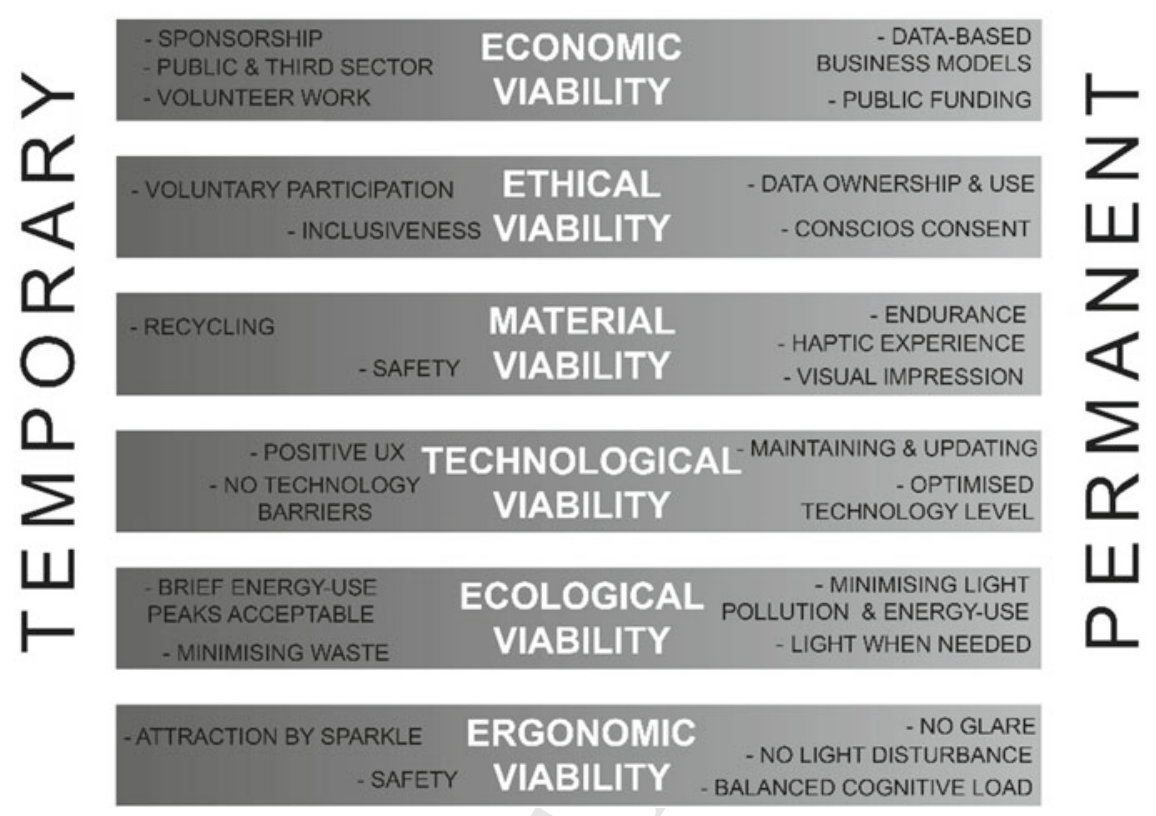

Fig. 13 Design aspects for viable playful and playable lighting

\section{Conclusion: Design Framework}

We first presented, in Fig. 12, the axis between playable and playful lighting, which highlighted the role of the audience of lighting installations, from spectatorship to participation. These were explored in relation to the empirical findings relating to our participants' experiences, resulting in four bands of experience: place, expression, meaning and play. Within all these experiential aspects, variation could be found depending on whether the installation was playable and engaged urban inhabitants in participation, or whether it was characterised as playful and invited people to attend in a role of a spectator. The playable projects managed to invite participants to play with lighting - a part of city infrastructure which traditionally is authorised only for the use and control of city authorities. They were engaged in self-expressing, creating meanings and gained ownership of public, urban place. With the playful projects, spectators received meanings, enjoyed aesthetic expressions and could be inspired to play by light, which all affected to their sense of place.

Second, we presented a thematisation of the critical scholarship relating to digital technologies as a part of contemporary and future life in cities. Our thematisation of the scholarship resulted in seven aspects that designers and policy-makers should 




Fig. 14 Design framework of viable playful and playable lighting

safeguard while implementing playful and playable lighting into urban places and spaces. These design aspects resonated with our own reflections of the case study design and realisation processes in several ways. In order to design playful and playable urban lighting that would viably support the wellbeing of urban inhabitants in the long term, we suggest the seven aspects presented in Fig. 13 as a check-list against which projects should be judged. The solutions or critical design issues listed under the check-list concern projects with different time-scales, both temporary and permanent.

In this final part of the chapter, we present and discuss a combination of these two earlier diagrams in Fig. 14 to arrive at a holistic model of designing viable playful and playable urban lighting.

The horizontal axis of the diagram represents the time scale of a lighting installation: whether it is temporary or permanent. As these kinds of technologies and smart 
city solutions are novel, it is still an open question what time scale should be considered as permanent in this context. We could define here a permanent installation of playable lighting to exist either on a basis of "for the foreseeable future" or for more than 5 years. More important than exact definitions, however, is the fact that at this end of the scale, novelty will no longer be a viable design option. In general, we argue, in order to design permanent playful and playable lighting, the design challenges are altered. The case studies and refence projects we have detailed in this chapter have all been more or less temporary. As an exception, the LightGame for Harbour Promenade was designed to be part of permanent smart city infrastructure, nevertheless, its realisation is still in the process. Thus, this is the empirical context where the design implications have also emerged. However, within this chapter, we have extended this through a review and thematisation of critical scholarship on digital technologies in cities. Combined with a reflection of our empirical experience, we argue for the careful consideration of seven important aspects that must be designed for in order to render lighting installations, including playful and playable lighting, viable in the long term. It must be noted that both temporary and permanent installations can be viable or successful in their own way, but they would require differing strategies regarding their design, implementation and upkeep. If these are not taken into consideration, there is a risk of arriving at the situation which we identified at the beginning of the LightStories project: the city had purchased the technology, but no one knew how-or by whom-it should be operated.

At the temporary end of the horizontal scale, we have also, within this chapter, identified two types of temporary installations: one-time (which may be longer or shorter standing) and reoccurring (as in the case of light festivals). These also present differing design challenges: as light festivals become an annual, expected event, they may experience some of the challenges that permanent installations face.

On the vertical axis of playful and playable are presented the positive experiences, which we recognised in the analysis of the participant feedback and the observations of the case study projects on site. These we want to emphasize as design targets for playful and playable lighting, amongst the other positive forms of experience which may emerge in different kind of contexts. We want to stress that even though one defining feature of play by Bateson and Martin [1] was "lack of practical goal or benefit", the experiences relating to playable and playful lighting, and to the playful actions the installations induce, are beneficial in many ways and may serve many practical design goals relating to smart cities. These include, for example, the strengthened sense and ownership of place, feeling of belonging, communal identity and increased sense of security. Furthermore, playful physical activities such as playing a LightGame or having walks in the nocturnal city, which has become more inviting, have positive health effects and increase well-being. We have also highlighted in the figure the two roles which urban dwellers can have in relation to playful and playable lighting - the spectatorship and participant. Both viewpoints are essential to consider in design processes.

Finally, as can be remarked from the seven design aspects which we have scrutinised in the chapter, design, realisation and maintenance of playful and playable lighting demand multidisciplinary expertise. No one field can master these chal- 
lenges, many of which are becoming more and more crucial in the age of climate change and artificial intelligence. We argue that a holistic understanding of the design task and successful realisation of projects can be gained only through co-operation of different fields and of different stakeholders of smart city development: designers, researchers, local people, city authorities, police-makers and private and third sector. The presented design framework can serve as a road-map in this collaboration.

Acknowledgements We thank the Academy of Finland and Tekes for funding the research projects, which have enabled our work: Adaptive Urban Lighting-Algorithm-Aided Lighting Design project (AF), WelLIT - Intelligent Lighting and Well-Being in Northern Learning Environments project (AF), Experiencing Artificial Intelligence in the Smart City: Co-creating applications for urban life (AF) and SenCity-Intelligent Light as Service Platform for Innovative Cities (Tekes). We also thank our fellow researchers in those research projects and all the participants of the case study projects. All the illustrations and photos are by Henrika Pihlajaniemi, except Fig. 2, which is by photographer Ilpo Aalto, published on courtesy of Tehomet Oy.

\section{References}

1. Bateson P, Martin P (2013) Play, Playfulness, Creativity and Innovation. Cambridge University Press, Cambridge

2. Bell JC (2009) Urban Otaku. Electric lighting and the noctambulist. AD 79(5):25-29

3. Boyce PR (2014) Human factors in lighting. CRC Press, Boca Raton

4. Brants K, Frissen V (2017) Inclusion and exclusion in the information society. In: R Silverstone (ed) Media, technology and everyday life in europe: from information to communication. Routledge, pp 39-50

5. Bridger R (2008) Introduction to ergonomics. CRC Press, Boca Raton

6. Cardullo P, Kitchin R (2018) Smart urbanism and smart citizenship: the neoliberal logic of 'citizen-focused' smart cities in Europe. Env Plann C Polit Space, 0263774X18806508

7. Chen C (2018) Designing the danceable city: how residents in Beijing cultivate health and community ties through urban dance. J Am Plann Assoc 84(3-4):237-249

8. Clarke RA (2003) Dataveillance-15 years on. Privacy Issues Forum 28

9. Dalsgaard P, Halskov K (2010) Designing urban media façades: cases and challenges. In: Proceedings of the SIGCHI conference on human factors in computing systems. ACM, New York, pp 2277-2286

10. Di Salvo C, Lukens J (2011) Nonanthropocentrism and the non-human in design: possibilities for designing new forms of engagement with and through technology. In: From social butterfly to engaged citizen: urban informatics, social media, ubiquitous computing, and mobile technology to support citizen engagement, $\mathrm{p} 421$

11. Falchi F, Cinzano P, Duriscoe D, Kyba CC, Elvidge CD, Baugh K, Portnov BA, Rybnikova NA, Furgoni R (2016) The new world atlas of artificial night sky brightness. Sci Adv 2(6):e1600377

12. Forlano L (2016) Decentering the human in the design of collaborative cities. Des Issues 32(3):42-54

13. Foth M, Caldwell GA (2018) More-than-human media architecture. In: Proceedings of the 4th media architecture biennale conference: digital infrastructure at the scale of the hybrid city. ACM, pp 66-75

14. Fritsch J, Brynskov M (2011) Between experience, affect, and information: experimental urban interfaces in the climate change debate. In: Foth M, Forlano L, Satchell C, Gibbs M (eds) From social butterfly to engaged citizen: urban informatics, social media, ubiquitous computing, and mobile technology to support citizen engagement. The MIT Press, pp 115-134 
15. Gitelman V, Zaidel, D, Doveh E (2012) Influence of billboards on driving behavior and road safety. Paper presented at the 18th international conference on traffic and transport psychology ICTTP, Groningen, The Netherlands

16. Hollands RG (2008) Will the real smart city please stand up? Intelligent, progressive or entrepreneurial? City 12(3):303-320

17. IDA (2019) URI: https://www.darksky.org/light-pollution/. Retrieved 2 May 2019

18. IEA (2019) URI: https://www.iea.cc/whats/index.html. Retrieved 2 May 2019

19. Kaleva (2006) URI: http://www.kaleva.fi/uutiset/oulu/joukkoraiskaus-keskella-oulua/121073/ . Retrieved 24 Oct 2015

20. Kaleva (2018) URI: https://www.kaleva.fi/uutiset/oulu/oliko-lumo-festivaalilla-yleisoa-lahestuplasti-suviseuroihin-verrattuna/811083/. Retrieved 7 Apr 2019

21. Kyba CC, Kuester T, De Miguel AS, Baugh K, Jechow A, Hölker F, Bennie J, Elvidge CD, Gaston KJ, Guanter L (2017) Artificially lit surface of Earth at night increasing in radiance and extent. Sci Adv 3(11):e1701528

22. Lam WM (1977) Perception and lighting as formgivers for architecture. In: Ripman CH (ed). McGraw-Hill, New York

23. Luusua A (2016) Experiencing and evaluating digital augmentation of public urban places. Doctoral dissertation. University of Oulu Graduate School; University of Oulu, Oulu School of Architecture, Acta Universitatis Ouluensis H 5

24. Luusua A, Pihlajaniemi H, Ylipulli J (2016) Northern urban lights: emplaced experiences of urban lighting as digital augmentation. Architecture and interaction. Springer International Publishing, pp 275-297

25. Luusua A, Ylipulli J, Kukka H, Ojala T (2017) Experiencing the hybrid city: the role of digital technologies in public urban places. The SAGE handbook of new urban studies. SAGE, London, pp 535-549

26. Luusua A, Ylipulli J, Rönkkö E (2017) Nonanthropocentric design and smart cities in the anthropocene. IT Inf Technol 59(6):295-304

27. Mariën I, Prodnik J (2014) Digital inclusion and user (dis) empowerment: a critical perspective. Info 16(6):35-47

28. Narboni R (2004) Lighting the landscape. Art design technologies. Birkhäuser, Basel

29. Nijholt A (2017) Towards playful and playable cities. In: A Nijholt (ed) Playable Cities. Springer, Singapore, pp 1-20

30. Ojala T, Kostakos V, Kukka H, Heikkinen T, Linden T, Jurmu M, Hosio S, Kruger F, Zanni D (2012) Multipurpose interactive public displays in the wild: three years later. Computer 45(5):42-49

31. Österlund T, Pihlajaniemi H (2015) VirtuAUL —a design framework for adaptive lighting. In: Proceedings of eCAADe 2015 conference, pp 201-210

32. Österlund T, Pihlajaniemi H (2017) Designing and controlling adaptive lighting using network based agents methodology. Nord J Archit Res 29(1):2017

33. Pihlajaniemi H (2016) Designing and experiencing adaptive lighting. Case studies with adaptation, interaction and participation. Doctoral dissertation. University of Oulu Graduate School, University of Oulu, Oulu School of Architecture, Acta Universitatis Ouluensis H 3

34. Pihlajaniemi H (2017) Smart lighting for urban experiences — engaging users for better services. In: Proceedings of professional lighting design convention 2017, VIA-Verlag, Gütersloh, pp $75-78$

35. Pihlajaniemi H, Juntunen E, Luusua A, Tarkka-Salin M, Juntunen J (2016) SenCity-piloting intelligent lighting and user-oriented services in complex smart city environments. In: Proceedings of eCAADe 2016 conference, pp 669-680

36. Pihlajaniemi H, Luusua A, Teirilä M, Österlund T, Tanska T (2012) Experiencing participatory and communicative urban lighting through LightStories. In: Proceedings of the 4th media architecture biennale conference: participation. ACM, New York, pp 65-74

37. Pihlajaniemi H, Österlund T, Herneoja A (2014). Urban echoes: adaptive and communicative urban lighting in the virtual and the real. In: MAB' 14 proceedings of the 2 nd media architecture biennale conference: world cities. ACM Digital Library, pp 48-57. ISBN: 978-1-4503-3302-3 
38. Pihlajaniemi H, Österlund T, Tanska T, Herneoja A, Valjus A (2013) 3 X interactive urban lighting: AUL demo cases. In: Interactive city lighting workshop in CHI 2013 conference. Paris, France, 27 Apr-2 May 2013

39. Qiang X (2019) The road to digital unfreedom: president Xi's surveillance state. J Democr 30(1):53-67

40. Salvendy G (ed) (2012) Handbook of human factors and ergonomics. Wiley

41. Schmidt A (2000) Implicit human computer interaction through context. Pers Technol 4(2-3):191-199

42. Stralen MDSV, Baltazar AP, Marques LM, Ferreira de Arruda G (2012) Congonhas media Cascade-Ituita: a permanent urban interactive interface for citizenship. In: Proceedings of eCAADe 2015 conference

43. Wachtel J (2009) Safety impacts of the emerging digital display technology for outdoor advertising signs. Final report. Veridian Group, Inc. Berkeley

44. Ylipulli J, Luusua A, Kukka H, Ojala T (2014) Winter is coming: introducing climate sensitive urban computing. In: Proceedings of the 2014 conference on designing interactive systems. ACM, New York, pp 647-656

45. Ylipulli J, Luusua A (2019) Without libraries what have we? Public libraries as nodes for technological empowerment in the era of smart cities, AI and big data. In: Proceedings of communities \& technologies (C\&T'19). ACM, New York (in press)

46. Zielinska-Dabkowska KM (2014) Critical perspectives on media architecture: is it still possible to design projects without negatively affecting urban nighttime environments and will the future remain dynamic, bright and multi-colored? In: Proceedings of the 2 nd media architecture biennale conference: world cities. ACM, New York, pp 101-108

47. Zuboff S (1985) Automate/informate: the two faces of intelligent technology. Org Dyn 14(2):5-18

48. Zuboff S (2015) Big other: surveillance capitalism and the prospects of an information civilization. J Inf Technol 30(1):75-89 